\title{
Relationship between Pigment Composition and Peel Color for the Fruit of Chinese Flame Tree
}

\author{
Yiguang Wang, Chao Zhang, Bin Dong, Yaohui Huang, Zhiyi Bao, and Hongbo Zhao' \\ Department of Ornamental Horticulture, School of Landscape Architecture, Zhejiang Agriculture \& \\ Forestry University, Lin'an 311300, Zhejiang, China
}

\begin{abstract}
AdDitional INDEX words. Sapindaceae, CIELAB, chlorophyll, carotenoids, anthocyanins, cyanidin 3-O-rutinoside
Abstract. Chinese flame tree (Koelreuteria bipinnata var. integrifoliola), a common ornamental tree in southern China, exhibits a variety of fruit colors among individual plants within the same cultivated field. In this study, 44 plants with different fruit colors were selected to investigate the impact of pigment composition on the coloration of fruit peels. The plants were divided into three groups based on the color phenotype of the fruit peel: red, pink, and green. The values of lightness $\left(L^{*}\right)$ were negatively correlated with redness $\left(a^{*}\right)$ and positively correlated with yellowness $\left(b^{*}\right)$. The correlations of chroma $\left(C^{*}\right)$ with the other color parameters differed among the three groups. In the pooled pink and red groups, $C^{*}$ was negatively correlated with both $L^{*}$ and $b^{*}$ and positively correlated with $a^{*}$, whereas the opposite relationships were found in the green group. According to the pigment analysis, anthocyanins, chlorophylls, and carotenoids were detected in the fruit peels. Anthocyanins were found to be the main pigment responsible for the differences in fruit color among the various groups. The highest anthocyanin content of fruit peel was found in the red group, followed by the pink group; the lowest anthocyanin levels appeared in the green group. The major anthocyanin component in the fruit peels was identified as cyanidin 3-O-rutinoside. By classifying fruit peel color and determining pigment composition, this study provides a theoretical basis for further researching genetic control and regulation of anthocyanin biosynthesis genes on pigment accumulation and peel coloration of chinese flame tree.
\end{abstract}

Koelreuteria bipinnata var. integrifoliola, known as the chinese flame tree, is a deciduous tree of the Sapindaceae family. Because of its high ornamental value and adaptability, chinese flame tree has been used extensively in landscaping in recent years and as a street tree to decorate cities in southern China. The trees of this species appear golden during the flowering period in late summer, and the optimal time to view the fruit is in autumn. In autumn, the branches of chinese flame tree are encrusted with lantern-like and membranous capsules, and the peels of fruit at the same developmental stage can display a variety of colors, including dark green, yellow green, light green, pink, and bright red.

Many factors affect the colors of ornamental plant tissues such as fruit and flowers. These factors include the composition and chemical structure of pigments, vacuolar $\mathrm{pH}$, cell shape, and environmental factors (Cooper-Driver, 2001). Among these factors, pigment composition and content are the most important. In addition to the chlorophylls commonly found in green tissues, flavonoids and carotenoids are main pigments determining the colors of plants (Tanaka et al., 2008). Anthocyanins are the most important flavonoids that affect the flower and fruit colors of plants, and they control the color change of plant tissues from pink, red, and purple to blue (Grotewold, 2006). Carotenoids are accessory components for photosynthesis and play important roles in photoprotection. In addition, a substantial accumulation of carotenoids in fruit and petals can result in yellow, orange, and red colors (Hirschberg, 2001; Ohmiya, 2013). All of these pigments are present in varying ratios in the fruit peel and exert significant effects on peel coloration. For instance, changes in the compositional

Received for publication 3 Jan. 2018. Accepted for publication 30 Apr. 2018. This work was supported by Zhejiang Provincial Major Program of New Cultivar Breeding (Grant no. 2012C12909-1).

${ }^{1}$ Corresponding author. E-mail: zhaohb@zafu.edu.cn. ratio of chlorophylls and carotenoids can promote color changes from green to yellow for the fruit peels of 'Le Lectier' pear [Pyrus communis (Charoenchongsuk et al., 2015)], mango [Mangifera indica (Rungpichayapichet et al., 2015)], and 'Valencia' sweet orange [Citrus sinensis (Wei et al., 2014)]. The peels of some other fruit contain a considerable amount of anthocyanins and, thus, appear red or purple when ripening; such fruits include apple [Malus sylvestris var. domestica (Honda et al., 2002)], grape [Vitis vinifera (Ortega-Regules et al., 2006)], and pomegranate [Punica granatum (Zhao et al., 2015)].

Previous studies on the fruit of Koelreuteria plants have primarily focused on methods of pigment abstraction from fruit peels and the identification of medicinal ingredients (Liang et al., 2005; Lin et al., 2014; Yang, 2008; Yuan et al., 2013). To our knowledge, little work has been dedicated to investigating fruit color of chinese flame tree, and no qualitative analysis of the major pigments in the fruit peel of this species has been reported. In the present study, the fruit color phenotype of different plants of chinese flame tree were determined using a colorimeter and then described and classified by using hierarchical cluster analysis (HCA). The effect of pigment composition on fruit coloration was then explored via Pearson correlation analysis and multiple linear regression (MLR) analysis. Furthermore, the structure of the major anthocyanin components in the fruit peel was identified by high-performance liquid chromatography with electrospray ionization and mass spectrometry (HPLC-ESI-MS). This work provides a physiological background, which includes classification of phenotypes and distinct metabolite in different individuals or groups of chinese flame tree, for further molecular studies on genetic control and regulation of anthocyanin biosynthesis in this plant. 


\section{Materials and Methods}

Plant materials. Most plants of chinese flame tree used in the market were obtained by seedling from seeds. The plants with colorful fruit among different individuals used in this research are older than 10 years and cultivated in a consistent growth environment in Hangzhou, China. Forty-four elite plants with representative fruit colors were selected. Three to four infructescences (with $\approx 30$ fruit per infructescence) from each individual plant were collected at the full bearing period in Oct. 2016 (the optimal viewing period for this fruit). After the removal of the seeds, the color phenotypes of the fruit peels were analyzed. The remaining fruit peels were dried with allochroic silica gel, ground into powder, and stored in darkness at $-20{ }^{\circ} \mathrm{C}$ before pigment analysis.

COLOR ANALYSIS OF FRUIT PEELS. The $L^{*}, a^{*}$, and $b^{*}$ of the fruit peels were measured using a portable colorimeter (CR-10; Konica Minolta, Tokyo, Japan) under constant light conditions. The $C^{*}$ and hue angle (h) of the fruit peels were calculated as follows: $C^{*}=\left(a^{* 2}+b^{* 2}\right)^{1 / 2}$ and $h=\arctan (b * / a *)$ (Gonnet, 1998). Each measurement was performed with five biologic replications.

Preliminary QUALITATIVE ANALYSIS OF PIGMENTS. For each sample, $0.1 \mathrm{~g}$ of powdered fruit peel was added to a test tube containing $5 \mathrm{~mL}$ of petroleum ether, $10 \% \mathrm{HCl}$, or $30 \% \mathrm{NH}_{3} \cdot \mathrm{H}_{2} \mathrm{O}$. After the mixture was oscillated and filtered, the color of the filtrate was observed (Bai et al., 2006). Equivalent powdered fruit peel from each sample was added to $5 \mathrm{~mL}$ of acetone: petroleum ether $(9: 1, \mathrm{v} / \mathrm{v})$, acetone: petroleum ether $(1: 1, \mathrm{v} / \mathrm{v})$, or $\mathrm{HCl}$ : methanol $(1: 99, \mathrm{v} / \mathrm{v})$ at $4{ }^{\circ} \mathrm{C}$ and left in darkness for $24 \mathrm{~h}$ for extraction. The extracts were diluted to a constant volume of $10 \mathrm{~mL}$ and then scanned by using an ultravioletvisible (ultraviolet-Vis) spectrophotometer (ultraviolet-3802; Shimadzu, Kyoto, Japan) within the ranges of 400-700, 200-700, and 220-600 nm (Bai et al., 2006; Zhao et al., 2004).

DETERMINATION OF TOTAL CHLOROPHYLL AND CAROTENOIDS. For each sample, $0.05 \mathrm{~g}$ of powder was added to $5 \mathrm{~mL}$ of $80 \%$ acetone in darkness at $4{ }^{\circ} \mathrm{C}$ and left for $24 \mathrm{~h}$. The extract was filtered through a $0.22-\mu \mathrm{m}$ membrane filter before analysis. The absorbance (A value) of the sample solution was measured at detection wavelengths of 470, 647, and $663 \mathrm{~nm}$ using an
ultraviolet-Vis spectrophotometer (ultraviolet-3802). Each sample was subjected to extraction and measured in three biologic replications. The concentrations of chlorophylls and carotenoids were calculated using the following formulae (Lichtenthaler, 1987):

Chlorophyll a(milligrams per liter $)=12.25 \mathrm{~A}_{663}-2.79 \mathrm{~A}_{647}$,

Chlorophyll $\mathrm{b}($ milligrams per liter $)=21.50 \mathrm{~A}_{647}-5.10 \mathrm{~A}_{663}$,

Total chlorophylls(milligrams per liter)

$$
=7.15 \mathrm{~A}_{663}+18.71 \mathrm{~A}_{647} \text {, }
$$

Table 1. Color parameters of the fruit peels of 44 samples determined by colorimeter $(n=5)$.

\begin{tabular}{|c|c|c|c|c|c|}
\hline \multirow[b]{2}{*}{ Sample no. } & \multicolumn{5}{|c|}{$\mathrm{CIE} L * a * b^{*}$ coordinate $(\text { mean } \pm \mathrm{SE})^{\mathrm{z}}$} \\
\hline & $L^{*}$ & $a^{*}$ & $b^{*}$ & $C^{*}$ & $h^{\mathrm{o}}$ \\
\hline$\overline{\mathrm{K} 1}$ & $46.24 \pm 0.78$ & $25.40 \pm 0.86$ & $16.54 \pm 0.45$ & $30.31 \pm 0.57$ & $0.58 \pm 0.03$ \\
\hline $\mathrm{K} 2$ & $48.42 \pm 0.87$ & $25.86 \pm 1.70$ & $16.80 \pm 0.91$ & $30.84 \pm 0.92$ & $0.58 \pm 0.06$ \\
\hline K3 & $68.92 \pm 1.86$ & $0.66 \pm 2.02$ & $31.12 \pm 0.63$ & $31.13 \pm 0.55$ & $1.55 \pm 0.71$ \\
\hline $\mathrm{K} 4 \mathrm{Z}$ & $60.38 \pm 2.54$ & $7.44 \pm 1.66$ & $26.48 \pm 1.51$ & $27.51 \pm 1.07$ & $1.30 \pm 0.07$ \\
\hline K5 & $57.08 \pm 2.00$ & $17.12 \pm 2.85$ & $20.54 \pm 1.16$ & $26.74 \pm 1.22$ & $0.88 \pm 0.11$ \\
\hline K6 & $49.54 \pm 0.95$ & $25.66 \pm 1.17$ & $17.14 \pm 0.46$ & $30.86 \pm 0.79$ & $0.59 \pm 0.03$ \\
\hline K7 & $66.50 \pm 1.45$ & $-4.08 \pm 1.60$ & $34.98 \pm 1.00$ & $35.22 \pm 1.14$ & $-1.45 \pm 0.04$ \\
\hline K8 & $57.48 \pm 0.56$ & $10.60 \pm 1.60$ & $24.74 \pm 1.23$ & $26.92 \pm 0.58$ & $1.17 \pm 0.07$ \\
\hline K9 & $63.46 \pm 1.42$ & $2.16 \pm 1.21$ & $30.34 \pm 0.88$ & $30.42 \pm 0.81$ & $1.50 \pm 0.60$ \\
\hline K10 & $48.14 \pm 1.56$ & $25.40 \pm 2.64$ & $19.26 \pm 1.23$ & $31.88 \pm 1.43$ & $0.65 \pm 0.08$ \\
\hline K11 & $64.00 \pm 1.50$ & $2.26 \pm 1.70$ & $30.16 \pm 0.83$ & $30.24 \pm 0.77$ & $1.50 \pm 0.59$ \\
\hline K12 & $42.86 \pm 1.61$ & $33.36 \pm 1.72$ & $13.44 \pm 0.69$ & $35.97 \pm 1.28$ & $0.38 \pm 0.04$ \\
\hline K13 & $58.24 \pm 3.27$ & $11.08 \pm 4.71$ & $22.42 \pm 1.41$ & $25.01 \pm 1.93$ & $1.11 \pm 0.53$ \\
\hline K14 & $49.14 \pm 1.28$ & $29.56 \pm 2.21$ & $16.18 \pm 0.57$ & $33.70 \pm 1.69$ & $0.50 \pm 0.05$ \\
\hline K15 & $53.62 \pm 1.19$ & $24.92 \pm 2.05$ & $18.38 \pm 0.40$ & $30.96 \pm 1.53$ & $0.64 \pm 0.05$ \\
\hline K16 & $48.72 \pm 2.01$ & $23.66 \pm 2.76$ & $19.12 \pm 0.79$ & $30.42 \pm 1.88$ & $0.68 \pm 0.07$ \\
\hline K17 & $54.00 \pm 2.25$ & $13.38 \pm 2.84$ & $24.18 \pm 1.66$ & $27.64 \pm 0.81$ & $1.07 \pm 0.11$ \\
\hline K18 & $51.34 \pm 1.75$ & $31.86 \pm 2.71$ & $16.46 \pm 0.53$ & $35.86 \pm 2.18$ & $0.48 \pm 0.05$ \\
\hline K19 & $58.26 \pm 1.67$ & $10.60 \pm 2.34$ & $25.30 \pm 1.52$ & $27.43 \pm 0.65$ & $1.17 \pm 0.10$ \\
\hline $\mathrm{K} 20$ & $51.24 \pm 1.54$ & $24.76 \pm 1.66$ & $18.16 \pm 1.11$ & $30.71 \pm 0.70$ & $0.63 \pm 0.06$ \\
\hline $\mathrm{K} 21$ & $54.42 \pm 1.29$ & $19.20 \pm 1.86$ & $21.22 \pm 0.97$ & $28.62 \pm 0.88$ & $0.84 \pm 0.07$ \\
\hline K22 & $62.62 \pm 3.06$ & $6.20 \pm 4.01$ & $28.58 \pm 1.92$ & $29.24 \pm 1.18$ & $1.36 \pm 0.52$ \\
\hline K23 & $55.88 \pm 1.21$ & $12.96 \pm 2.13$ & $23.26 \pm 0.97$ & $26.63 \pm 0.34$ & $1.06 \pm 0.09$ \\
\hline K24 & $58.78 \pm 2.92$ & $16.30 \pm 4.58$ & $20.60 \pm 1.52$ & $26.27 \pm 1.80$ & $0.90 \pm 0.16$ \\
\hline K25 & $55.64 \pm 1.22$ & $14.16 \pm 2.35$ & $25.18 \pm 1.54$ & $28.89 \pm 0.45$ & $1.06 \pm 0.09$ \\
\hline K26 & $54.60 \pm 3.18$ & $14.54 \pm 4.24$ & $21.78 \pm 2.72$ & $26.19 \pm 0.50$ & $0.98 \pm 0.18$ \\
\hline $\mathrm{K} 27$ & $46.26 \pm 1.29$ & $35.88 \pm 1.71$ & $15.18 \pm 0.61$ & $38.96 \pm 1.35$ & $0.40 \pm 0.03$ \\
\hline K28 & $53.64 \pm 1.74$ & $32.34 \pm 2.61$ & $15.12 \pm 0.60$ & $35.70 \pm 2.11$ & $0.44 \pm 0.05$ \\
\hline K29 & $63.24 \pm 1.62$ & $11.44 \pm 2.16$ & $27.06 \pm 0.94$ & $29.38 \pm 0.55$ & $1.17 \pm 0.08$ \\
\hline $\mathrm{K} 30$ & $52.92 \pm 1.71$ & $28.40 \pm 2.56$ & $16.52 \pm 0.89$ & $32.86 \pm 1.75$ & $0.53 \pm 0.06$ \\
\hline K31 & $50.30 \pm 1.26$ & $26.56 \pm 1.99$ & $18.60 \pm 0.62$ & $32.43 \pm 1.36$ & $0.61 \pm 0.05$ \\
\hline K32 & $58.02 \pm 1.75$ & $16.02 \pm 3.07$ & $22.44 \pm 1.68$ & $27.57 \pm 1.91$ & $0.95 \pm 0.10$ \\
\hline K33 & $60.02 \pm 1.27$ & $9.16 \pm 1.37$ & $26.54 \pm 1.01$ & $28.08 \pm 0.61$ & $1.24 \pm 0.06$ \\
\hline K34 & $52.84 \pm 2.62$ & $21.96 \pm 3.69$ & $19.08 \pm 2.06$ & $29.09 \pm 1.45$ & $0.72 \pm 0.13$ \\
\hline K35 & $55.16 \pm 2.08$ & $18.82 \pm 3.17$ & $21.22 \pm 1.63$ & $28.36 \pm 0.74$ & $0.85 \pm 0.12$ \\
\hline K36 & $54.96 \pm 1.95$ & $23.24 \pm 2.52$ & $20.66 \pm 1.12$ & $31.10 \pm 1.20$ & $0.73 \pm 0.08$ \\
\hline K37 & $50.60 \pm 2.98$ & $17.54 \pm 3.76$ & $22.56 \pm 2.24$ & $28.58 \pm 0.40$ & $0.91 \pm 0.15$ \\
\hline K38 & $65.14 \pm 2.79$ & $2.04 \pm 4.07$ & $32.06 \pm 2.11$ & $32.12 \pm 1.82$ & $1.51 \pm 0.65$ \\
\hline K39 & $61.82 \pm 2.09$ & $5.52 \pm 1.57$ & $28.90 \pm 0.65$ & $29.42 \pm 0.40$ & $1.38 \pm 0.06$ \\
\hline K40 & $52.18 \pm 1.99$ & $19.30 \pm 3.61$ & $21.08 \pm 1.83$ & $28.58 \pm 0.62$ & $0.83 \pm 0.14$ \\
\hline K41 & $49.02 \pm 1.91$ & $32.72 \pm 2.35$ & $15.72 \pm 1.08$ & $36.30 \pm 1.74$ & $0.45 \pm 0.06$ \\
\hline K42 & $45.92 \pm 1.39$ & $32.28 \pm 2.94$ & $13.94 \pm 0.61$ & $35.16 \pm 2.46$ & $0.41 \pm 0.05$ \\
\hline K43 & $60.94 \pm 2.81$ & $12.30 \pm 3.27$ & $24.34 \pm 1.59$ & $27.27 \pm 0.37$ & $1.10 \pm 0.13$ \\
\hline K44 & $64.14 \pm 1.30$ & $7.98 \pm 2.00$ & $25.44 \pm 0.91$ & $26.66 \pm 0.65$ & $1.27 \pm 0.08$ \\
\hline
\end{tabular}

${ }^{\mathrm{z}} L^{*}=$ lightness; $a^{*}$ and $b^{*}=$ chromatic components; $C^{*}=$ chroma; $h^{\circ}=$ hue angle. 
Total carotenoids (milligrams per liter)

$=\left(1000 \mathrm{~A}_{470}-1.82\right.$ Chlorophyll $\mathrm{a}+85.02$ Chlorophyll $\left.\mathrm{b}\right) / 198$.

Determination of total anthocyanins. A pH differential method was used to determine total anthocyanin content (Patil and Raghavarao, 2007). First, $0.05 \mathrm{~g}$ of sample powder was added to $3 \mathrm{~mL}$ of $0.1 \% \mathrm{HCl}$ in methanol at $4{ }^{\circ} \mathrm{C}$ in darkness and left in darkness for $24 \mathrm{~h}$ for extraction. The extract was filtered using a $0.22-\mu \mathrm{m}$ membrane filter and then stored at $4{ }^{\circ} \mathrm{C}$ until analysis. A $1-\mathrm{mL}$ portion of extract was added to $4 \mathrm{~mL}$ of $0.4 \mathrm{~mol} \cdot \mathrm{L}^{-1} \mathrm{NaAc}$ buffer ( $\left.\mathrm{pH} 4.5\right)$, and another $1 \mathrm{~mL}$ of extract was added to $0.25 \mathrm{~mol} \cdot \mathrm{L}^{-1} \mathrm{NaCl}$ buffer $(\mathrm{pH} 1.0)$. The mixtures were shaken and then transferred to cuvettes with a path length of $1 \mathrm{~cm}$. The absorbance of the sample solutions at $520 \mathrm{~nm}\left(\mathrm{~A}_{520}\right)$ and $700 \mathrm{~nm}\left(\mathrm{~A}_{700}\right)$ was measured. Extraction and measurement were repeated three times for each sample. Total anthocyanin content was calculated according to the equation: Total anthocyanins (milligrams per liter) $=\mathrm{A} \times \mathrm{Mw} \times \mathrm{DF} \times 10^{3} /(\varepsilon \times L)$, where the absorbance $A$ was calculated as $A=\left(A_{520}-A_{700}\right)$ pH1.0 $-\left(\mathrm{A}_{520}-\mathrm{A}_{700}\right)_{\mathrm{pH} 4.5}$; Mw denotes the molecular weight of anthocyanins $\left(433.2 \mathrm{~g} \cdot \mathrm{mol}^{-1}\right), \mathrm{DF}$ is the dilution factor, $\varepsilon$ expresses the extinction coefficient $\left(29,600 \mathrm{~L} \cdot \mathrm{mol}^{-1} \cdot \mathrm{cm}^{-1}\right)$, and $\mathrm{L}$ is the path length $(1 \mathrm{~cm})$.

Structural identification of Anthocyanins. A $0.05 \mathrm{~g}$ portion of powdered fruit peel from each sample was added to $5 \mathrm{~mL}$ of $70 \%$ methanol (containing $0.1 \% \mathrm{HCl}$ ) (Yang et al., 2009) for extraction. After $24 \mathrm{~h}$ of extraction in the dark at $4{ }^{\circ} \mathrm{C}$, the extracts were centrifuged at 14,167 $g_{n}$ for $5 \mathrm{~min}$. The supernatant was filtered through a $0.22-\mu \mathrm{m}$ membrane filter and then stored at $-20^{\circ} \mathrm{C}$ in the dark until HPLC-MS analysis. HPLC analysis was carried out using a Shimadzu HPLC system equipped with an LC-20AT pump, an SPD-M20A DAD detector, a CTO-10AS VP column oven, and an SIL-20A auto injector. The HPLC column was an Inertsil ODS SP C18 column (4.6 $\mathrm{mm} \times$ $250 \mathrm{~mm}, 5 \mu \mathrm{m}$; Shimadzu, Kyoto, Japan). For mobile phases A and B, $2 \%$ formic acid in water and $0.1 \%$ formic acid in acetonitrile, respectively, were used. The analysis conditions were as follows: scan range from 190 to $800 \mathrm{~nm}$, detection wavelength of $520 \mathrm{~nm}$, column temperature of $35{ }^{\circ} \mathrm{C}$, flow rate of $0.8 \mathrm{~mL} \cdot \mathrm{min}^{-1}$, and injection volume of $10 \mu \mathrm{L}$. The gradient elution programs were as follows: $0 \mathrm{~min}, 10 \%$ $\mathrm{B}$; $20 \mathrm{~min}, 52 \% \mathrm{~B}$; $35 \mathrm{~min}, 80 \% \mathrm{~B}$; $37 \mathrm{~min}, 80 \% \mathrm{~B}$; and $40 \mathrm{~min}, 10 \% \mathrm{~B}$. An ion trap mass spectrometer (Thermo Fisher Scientific, Waltham, MA) equipped with an ESI interface was used for identification of anthocyanins. The MS conditions were as follows: positive ion mode, range of $m / z$ 160-1000 $\mathrm{u}$ for full-scan MS analysis, nitrogen as the drying gas and nebulizing gas, flow rate of $6 \mathrm{~L} \cdot \mathrm{min}^{-1}$, drying gas temperature of $350{ }^{\circ} \mathrm{C}$, nebulizer pressure of $206.84 \mathrm{kPa}$, and capillary voltage of $4 \mathrm{kV}$. The tentative identified compound based on MS information was further confirmed by comparing the retention time $(12.37 \mathrm{~min})$ and characteristic ultraviolet absorption peaks (280 and $518 \mathrm{~nm}$ ) with those of the standard [cyanidin 3-O-rutinoside (CAS 18719-76-1; Sigma-Aldrich, St. Louis, MO)].

STATistical anAlysis. HCA with the method of betweengroup linkage based on the color parameters of fruit peels was performed to classify the selected plants. The least significant difference test was used to detect the variance of pigment contents. Pearson correlation analysis and MLR were performed to explore the relationship between color phenotype and pigment composition in the fruit peels. All the statistical analyses were performed by using IBM SPSS Statistics (version 19.0; IBM, Armonk, NY).

\section{Results}

Color ANALYSis of FRUIT PEels. The color parameters (Table 1) of the fruit peels were determined by using a colorimeter. An HCA was then conducted on the 44 samples based on these parameters (Fig. 1). The samples were divided into three types at a clustering distance of 10 , with 18 samples

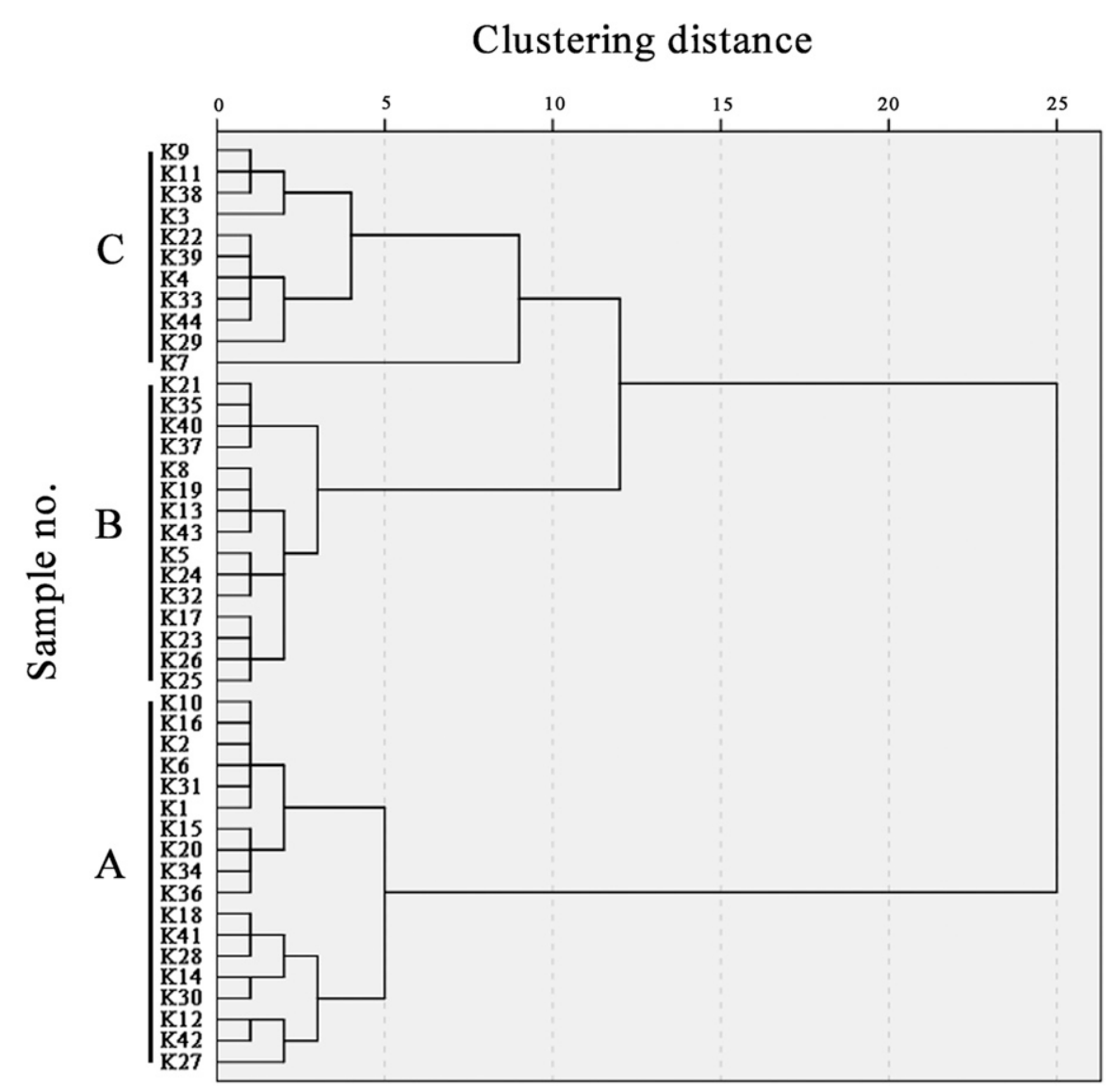

Fig. 1. Dendrogram using average linkage (between group) of the hierarchical cluster of different samples based on CIE $L^{*} a^{*} b^{*}$ of fruit peels ( $L^{*}=$ lightness, $a^{*}$ and $b^{*}=$ chromatic components, $C^{*}=$ chroma, and $h^{\circ}=$ hue angle). The sample numbers correspond to those in Table 1. 
for type A, 15 samples for type B, and 11 samples for type C. Visual observation (Fig. 2) revealed that the fruit color was bright red for most of the type A samples, which were collectively defined as the red group, a light red for the type B samples, which were collectively defined as the pink group, and yellowish-green/green for the type C samples, which were collectively defined as the green group.

Samples of different colors were clearly distinguished in the two-dimensional quadrants of the CIE $L * a * b *$ color system, which showed an obvious zonal distribution in the twodimensional quadrants formed by bivariate plots of $L^{*}, a^{*}$, and $b^{*}$ values. The red group had relatively low $L^{*}$ values (ranging from 42.86 to 53.64 ) and $b^{*}$ values (ranging from 13.94 to 20.66), but high $a^{*}$ values (ranging from 21.96 to $35.88)$. By contrast, the green group had a relatively high $L^{*}$ value (ranging from 60.38 to 68.92 ) and $b^{*}$ values (ranging from 25.44 to 34.98 ) but low $a^{*}$ values (ranging from -4.08 to 11.44). The pink group had intermediate $L^{*}$ values (ranging from 50.60 to 60.94 ), $a^{*}$ values (ranging from 10.60 to 19.30 ), and $b^{*}$ values (ranging from 20.54 to 25.30 ) relative to the values of the other two groups. A comparison of the $C^{*}$ values of samples among the three color groups revealed that the pink group had the lowest $C^{*}$, ranging from 25.01 to 28.89 , whereas the red and green groups had $C^{*}$ values ranging from 30.31 to 38.96 and 26.66 to 35.22 , respectively, with no significant difference between the latter two groups.

Despite their significantly different distributions between the color coordinate axes, $L^{*}, a^{*}$, and $b^{*}$ showed similar relationships and variations among the three groups. A significant negative correlation was found between $L^{*}$ and $a^{*}$ (Fig. $3 \mathrm{~A})$, the values of which were distributed along the fitted curve $y=-1.4961 x+100.54\left(R^{2}=0.8307\right)$. A significant positive correlation was found between $L^{*}$ and $b^{*}$ (Fig. 3B), and the fitted curve was $y=0.7754 x-20.92\left(R^{2}=\right.$ $0.8300)$. In addition, $b^{*}$ decreased with increasing $a^{*}$ (Fig. 3C), and the fitted curve was $y=-0.5053 x+$ $30.959\left(R^{2}=0.9496\right)$, with a high level of fit.

In the two-dimensional quadrants formed by $C^{*}$ and the other three color parameters, samples from the red and pink groups exhibited similar trends, whereas those from the green group showed the opposite trend. The fitted curves are as follows:

$C^{*}$ and $L^{*}$ (Fig. 3D): the pooled pink and red groups, $y=-0.6031 x+$ $62.154\left(R^{2}=0.5531\right)$; green population, $y=0.5911 x-7.6802\left(R^{2}=\right.$ 0.4211);

$C^{*}$ and $a^{*}$ (Fig. 3E): the pooled pink and red groups, $y=0.4455 x+$ $20.593\left(R^{2}=0.9034\right)$; green population, $y=-0.4509 x+32.029\left(R^{2}=\right.$ $0.7293)$; and

$C^{*}$ and $b^{*}$ (Fig. 3F): the pooled pink and red groups, $y=-0.8757 x+$ $47.591\left(R^{2}=0.7113\right)$; green population, $y=0.8079 x+6.3232\left(R^{2}=\right.$ 0.9532).

According to the fitted curves, $C^{*}$ of the pooled pink and red groups was significantly negatively correlated with $L^{*}$ and $b^{*}$ and significantly positively correlated with $a^{*}$. By contrast, in the green group, $C^{*}$ was significantly positively correlated with both $L^{*}$ and $b^{*}$ and significantly negatively correlated with $a^{*}$.

Determination OF PIgMENT TYPES IN THE FRUIT PEELS. The pigment types in the fruit peels of different color groups were determined by using a characteristic color reaction

Fig. 2. Fruit of chinese flame tree from different color groups. The sample numbers are corresponding to those in Fig. 1 and Table 1. 
and ultraviolet-Vis absorption spectral analysis (Table 2). Samples of all three color groups appeared to be pale yellow following reaction with petroleum ether, and the acetone: petroleum ether solution $(1: 1, \mathrm{v} / \mathrm{v})$ showed a weak shoulder
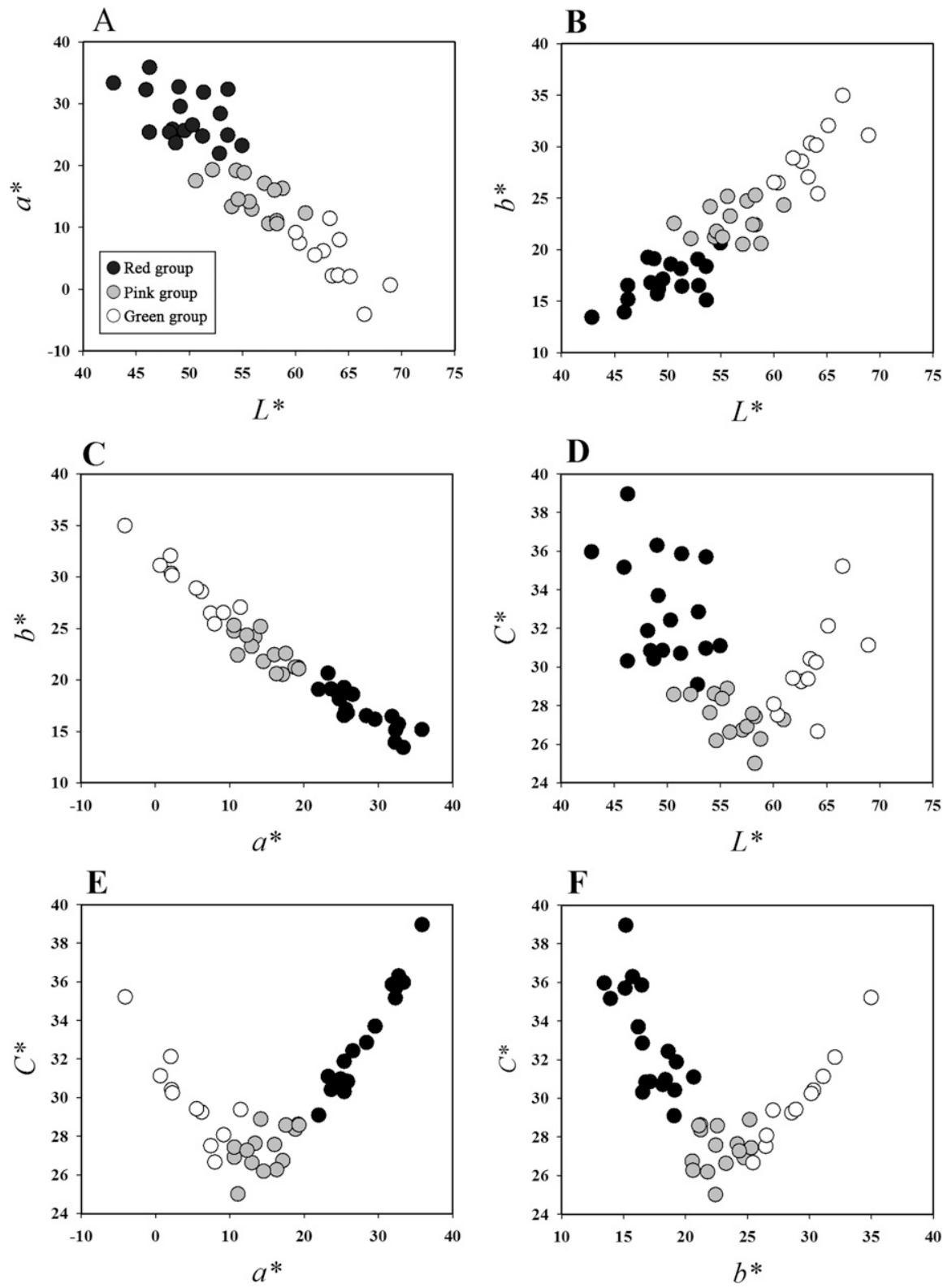

Fig. 3. Scattergrams of the color parameters of the fruit peels of chinese flame tree: (A) two-dimensional quadrant of $L^{*}$ and $a^{*}$; (B) two-dimensional quadrant of $L^{*}$ and $b^{*}$; (C) two-dimensional quadrant of $a^{*}$ and $b^{*}$; (D) twodimensional quadrant of $L^{*}$ and $C^{*} ;(\mathbf{E})$ two-dimensional quadrant of $a^{*}$ and $C^{*}$; and $(\mathbf{F})$ two-dimensional quadrant of $b^{*}$ and $C^{*}\left(L^{*}=\right.$ lightness, $a^{*}$ and $b^{*}=$ chromatic components, $C^{*}=$ chroma, $h^{\circ}=$ hue angle $)$. peak at $450 \mathrm{~nm}$, indicating a small amount of carotenoids in the fruit peels. The acetone: petroleum ether solution $(9: 1, \mathrm{v} / \mathrm{v})$ of all the samples showed an absorption peak in the vicinity of 660 $\mathrm{nm}$, indicating the presence of chlorophylls. The $\mathrm{HCl}-$ methanol solution $(1: 99, \mathrm{v} / \mathrm{v})$ of samples from red and pink groups showed absorption peaks at 529 and $528 \mathrm{~nm}$, respectively. In addition, the extracts from samples of the red group appeared pink in $10 \% \mathrm{HCl}$ solution, whereas those of the pink group were pale pink, which indicated that there were distinct levels of anthocyanins in the fruit of these two groups. In the green group, the $10 \% \mathrm{HCl}$ solution of most samples was colorless, and the test solution of only a few samples became pale pink. In addition, the $\mathrm{HCl}-$ methanol solution $(1: 99, \mathrm{v} / \mathrm{v})$ for samples from the green group showed no obvious absorption peak in the vicinity of $520 \mathrm{~nm}$, indicating the absence or only a trace amount of anthocyanins in the fruit peel of this group. On the other hand, by using $30 \% \mathrm{NH}_{3} \cdot \mathrm{H}_{2} \mathrm{O}$, flavonoids were detected in all three groups.

Pigment Contents of The Fruit PEELS. Given the strong coloring effects of chlorophylls, carotenoids, and anthocyanins on plant organs, the contents of these three types of pigments in the fruit peels were determined (Fig. 4). Among samples from the red group, the chlorophyll content ranged from 0.43 to $0.93 \mathrm{mg} \cdot \mathrm{g}^{-1}$, and the carotenoid content ranged from 0.20 to $0.45 \mathrm{mg} \cdot \mathrm{g}^{-1}$. The anthocyanin content varied over a wider range, from 0.36 to $2.13 \mathrm{mg} \cdot \mathrm{g}^{-1}$. Samples from the pink group had chlorophyll contents from 0.53 to $0.93 \mathrm{mg} \cdot \mathrm{g}^{-1}$, carotenoid contents ranging from 0.26 to $0.49 \mathrm{mg} \cdot \mathrm{g}^{-1}$, and anthocyanin contents of $0.22-0.76 \mathrm{mg} \cdot \mathrm{g}^{-1}$. Samples from the green group contained $0.58-0.92 \mathrm{mg} \cdot \mathrm{g}^{-1}$ chlorophylls, $0.32-0.49 \mathrm{mg} \cdot \mathrm{g}^{-1}$ carotenoids, and $0.18-0.48 \mathrm{mg} \cdot \mathrm{g}^{-1}$ anthocyanins.

Table 2. Color reaction and ultraviolet-visible absorption spectra of pigments in the fruit peels of samples in the three color groups of chinese flame tree.

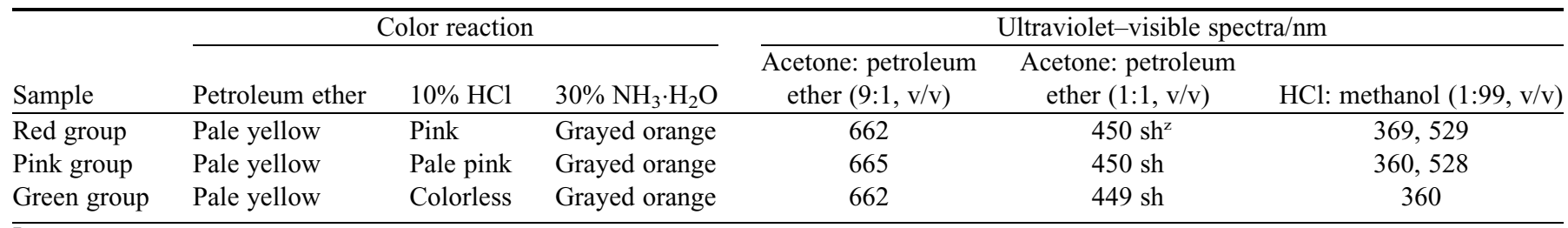

${ }^{\mathrm{z}} \mathrm{sh}=$ shoulder peak. 

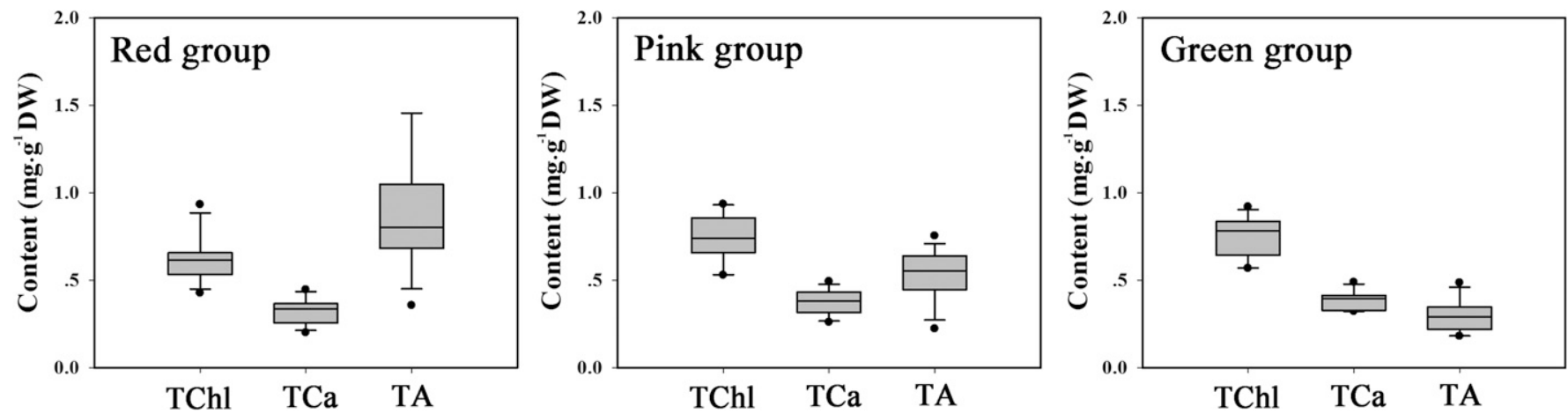

Fig. 4. Pigment composition in the fruit peels of chinese flame tree from different color groups $(\mathrm{TChl}=$ total chlorophylls; $\mathrm{TCa}=$ total carotenoids; and $\mathrm{TA}=$ total anthocyanins).

A variance analysis (Fig. 5) showed that the chlorophyll and carotenoid contents did not significantly differ between the green and pink groups and were both higher than those of the red group ( $P \leq$ 0.05 ). The anthocyanin content was highly significantly different among the three color groups. The samples in the red group showed the highest anthocyanin content, followed by the pink group; the lowest content was found in the green group.

Relationship BETWEeN COLOR PHENOTYPE AND PIGMENT CONTENTS IN THE FRUIT PEels. A Pearson correlation analysis was used to investigate the relationships between the color phenotype parameters and the pigment components in the fruit peels (Table 3). Both chlorophyll content and carotenoid content showed highly significant negative correlations with $a^{*}$ and $C^{*}$, whereas carotenoid content had a highly significant positive correlation with $b^{*}$. In addition, the contents of chlorophyll and carotenoid were highly correlated with one another, with the correlation coefficient reaching 0.993 . In addition, total anthocyanin content showed highly significant correlations with all the color parameters. Negative correlations were observed with $L^{*}$ and $b^{*}$, and positive correlations were observed with $a^{*}$ and $C^{*}$, with higher correlation coefficients compared with the other two types of pigments.

To further explore the contribution of pigments to fruit color formation, an MLR analysis was performed, with the fruit color parameters as the independent variables and pigment content as the dependent variable. Variables with the lowest $F$ values were omitted by a stepwise method, and MLR equations were established as follows:

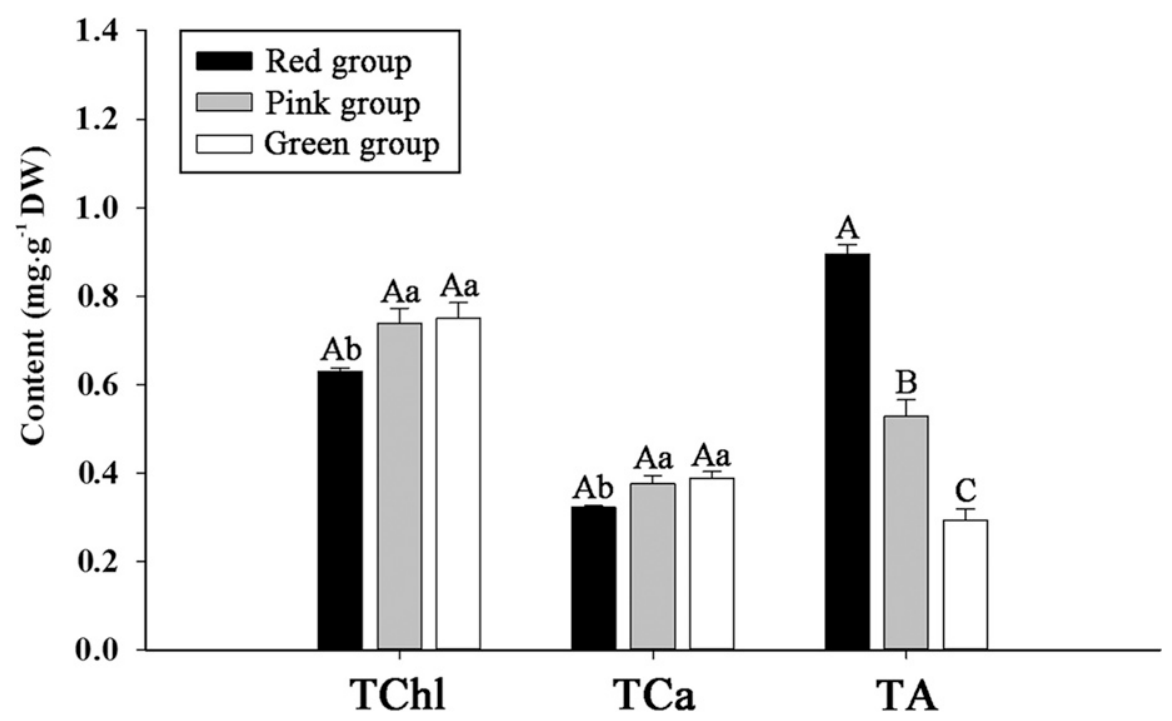

Fig. 5. Differences in the content of each pigment in the fruit peels among the three color groups of chinese flame tree. A, B, and $\mathrm{C}$ indicate significant differences at $P \leq 0.01$ level; $\mathrm{a}, \mathrm{b}$, and $\mathrm{c}$ indicate significant differences at $P$ $\leq 0.05$ level $(\mathrm{TChl}=$ total chlorophylls; $\mathrm{TCa}=$ total carotenoids; and $\mathrm{TA}=$ total anthocyanins $)$.

Table 3. Correlation analysis of fruit color and total contents of chlorophylls (TChl), carotenoids (TCa), and anthocyanins (TA) in chinese flame tree.

\begin{tabular}{|c|c|c|c|c|c|c|c|c|}
\hline & \multicolumn{8}{|c|}{ Pearson correlation $^{z}$} \\
\hline & $L^{*}$ & $a^{*}$ & $b^{*}$ & $C^{*}$ & $h^{\circ}$ & TChl & $\mathrm{TCa}$ & $\mathrm{TA}$ \\
\hline$L^{*}$ & 1 & & & & & & & \\
\hline$a^{*}$ & $-0.911 * *$ & 1 & & & & & & \\
\hline$b^{*}$ & $0.911 * *$ & $-0.974 * *$ & 1 & & & & & \\
\hline$C^{*}$ & $-0.422 * *$ & $0.548 * *$ & $-0.398 * *$ & 1 & & & & \\
\hline$h^{\mathrm{o}}$ & $0.417 * *$ & $-0.420 * *$ & $0.368^{*}$ & $-0.578 * *$ & 1 & & & \\
\hline TChl & 0.201 & $-0.454 * *$ & $0.372^{*}$ & $-0.452 * *$ & 0.151 & 1 & & \\
\hline $\mathrm{TCa}$ & 0.195 & $-0.463^{* *}$ & $0.399 * *$ & $-0.393 * *$ & 0.153 & $0.933^{* *}$ & 1 & \\
\hline TA & $-0.698 * *$ & $0.737 * *$ & $-0.745^{* *}$ & $0.519 * *$ & $-0.404 * *$ & $-0.344^{*}$ & $-0.393 * *$ & 1 \\
\hline
\end{tabular}

${ }^{\bar{z}} L^{*}=$ lightness; $a^{*}$ and $b^{*}=$ chromatic components; $C^{*}=$ chroma; $h^{\circ}=$ hue angle.

$*, * *$ Significant at $P \leq 0.05$ or 0.01 , respectively. 

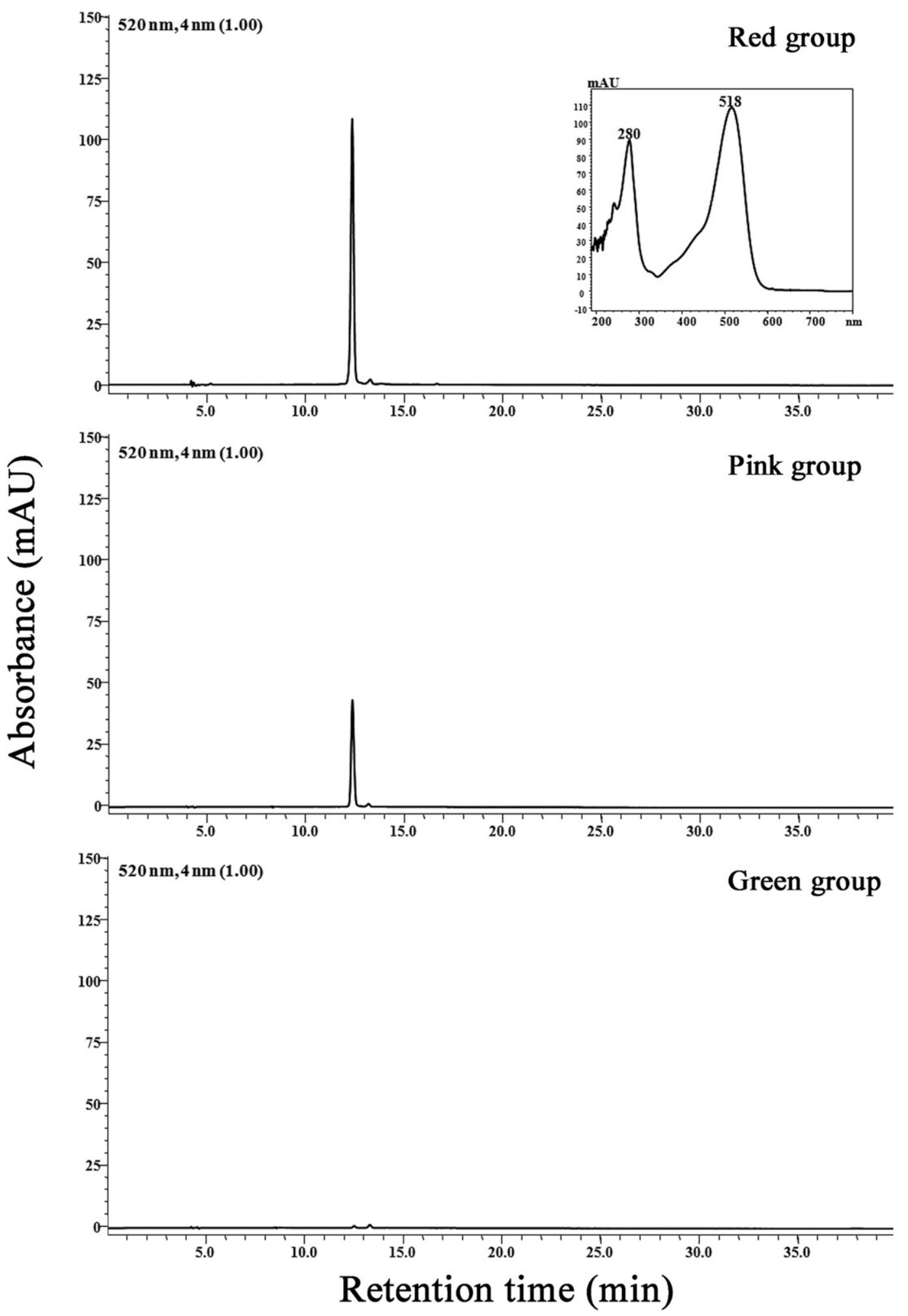

Fig. 6. High-performance liquid chromatography chromatogram and ultraviolet absorption peaks of anthocyanin from the fruit peels of chinese flame tree.

$$
\begin{gathered}
C^{*}=33.074+3.685 \mathrm{TA}-7.254 \mathrm{TChl}\left(R^{2}=0.354\right), \\
h=1.184-0.548 \mathrm{TA}\left(R^{2}=0.163\right) .
\end{gathered}
$$

The regression equations showed that anthocyanins made large contributions to all the color parameters. In addition, $a^{*}$ and $C^{*}$ were affected by total chlorophyll content. In conclusion, anthocyanins were the primary pigment that affected fruit color in the studied plants of $K$. bipinnata var. integrifoliola.

QUALITATIVE ANALYSIS OF ANTHOCYANINS IN THE FRUIT PEELS. In the HPLC-MS analysis of anthocyanin extracts obtained from the fruit peels, one major component with characteristic 
ultraviolet absorption peaks at 280 and $518 \mathrm{~nm}$ was detected (Fig. 6). The precursor ion of $m / z 595.2[\mathrm{M}+\mathrm{H}]^{+}$was obtained by $\mathrm{MS}$, and the fragment ions of $m / z 449.1$ and $m / z 287.4\left[\mathrm{Y}_{0}\right]^{+}$ were obtained by MS/MS (Fig. 7). Of these, $m / z 287.4\left[\mathrm{Y}_{0}\right]^{+}$ corresponded to the characteristic aglycone cation of cyanidin $(\mathrm{m} / \mathrm{z} 287)$. From the precursor ion to the two fragment ions, $m / z$ $146 \mathrm{u}$ and $m / z 162 \mathrm{u}$ were lost, which corresponded to the molecular weights of rhamnoside and glucoside, respectively. Thus, this component was identified as cyanidin with the glycosylation of the disaccharide. Because the ratio between the absorbance at $440 \mathrm{~nm}$ and the $\lambda$ vis-max of the component $\left(\mathrm{A}_{440} / \mathrm{A}_{\text {vis-max }}\right)$ was $29.6 \%$, the glycosides were supposed to be placed in the third position (Harborne, 1963). Based on the relative abundance of $\mathrm{Y}_{1}^{+}>\mathrm{Y}_{0}^{+}$, a $1 \rightarrow 6$ linkage between rhamnoside and glucoside was further confirmed (Ma et al., 2001). Finally, the component was identified as cyanidin 3-Orutinoside.

\section{Discussion}

By using the CIE $L * a * b^{*}$ color system, different plants of chinese flame tree were clearly divided into three color groups: red, pink, and green. In the red group, the fruit peel showed a darker and more reddish color than that of the other two groups. By contrast, the peels of samples from the green group had lower $a^{*}$ and higher $L^{*}$. The peels from samples in the pink group were intermediate in $L^{*}$ and $a^{*}$ relative to those of the other two groups and they ranked lowest for $C^{*}$. In addition, significant correlations between the different color parameters of the fruit peel were found. $L^{*}$ showed a significant negative correlation with $a^{*}$ and a significant positive correlation with $b^{*}$. Moreover, the relationships between $C^{*}$ and the other color parameters differed among the color groups. In the red-pink population, $C^{*}$ was negatively correlated with $L^{*}$ and $b^{*}$ and positively correlated with $a^{*}$. The opposite trends were found in the green group, resulting in a distinct $\mathrm{V}$ pattern in the twodimensional quadrant of color parameters (Fig. 3). Similar differences have been found in other plant species. For instance, based on a study of flower color phenotypes in 446 individuals of Paeonia rockii, $\mathrm{Wu}$ et al. (2016) found that $C^{*}$ had a significant negative correlation with $L^{*}$ in pale pink, pink, and blue groups, whereas it increased significantly with increasing $L^{*}$ in red, purple, and black groups. Moreover, in another study, different cultivars of Chrysanthemum morifolium showed no significant correlation between $C^{*}$ and $L^{*}$ changes in white, yellow, and yellow green groups, whereas a significant negative correlation was found between $C^{*}$ and $L^{*}$ in pink, red, purple, dark red, orange, and brown groups (Hong et al., 2012).

In our work, differences in pigment composition were found to be the primary cause of variation in fruit color for chinese flame tree. The anthocyanin content of the fruit peels differed significantly among the three color groups. The pink and green groups had higher contents of chlorophylls and carotenoids than did the red group; however, the pink group showed similar color variation as the red group. This finding indicates that in the green group, which had a low anthocyanin content, chlorophylls and carotenoids were the major pigments in the fruit peel, leading to variation in $C^{*}$. According to the Pearson correlation and MLR analyses, carotenoids made the smallest contribution to fruit color. The carotenoid and chlorophyll contents were positively correlated with one another. Thus, it can be speculated that most of the carotenoids in the studied fruit peels of chinese flame tree were chloroplast carotenoids, which play a more dominant role in photosynthesis rather than coloration (Green and Durnford, 1996). In summary, the major components that led to color differences in the various color groups of chinese flame tree were anthocyanins, and their content significantly affected all the color parameters. In particular, anthocyanin content showed significant negative correlations with $L^{*}$ and $b^{*}$ and significant positive correlations with $a^{*}$ and $C^{*}$. Previous studies showed that anthocyanin content had similar effects on $L^{*}$ and $a^{*}$ of flower petals, including those of Senecio cruentus (Sun et al., 2009),

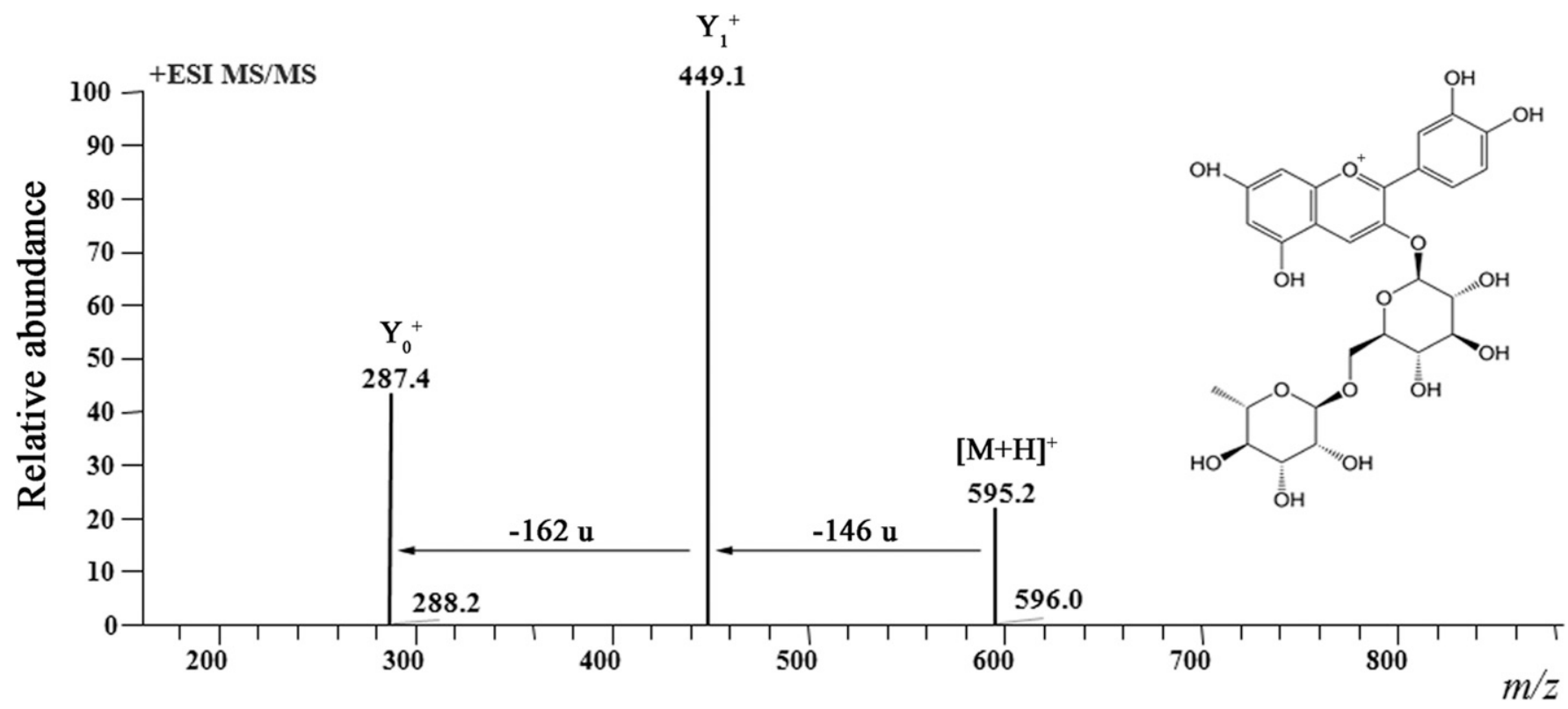

Fig. 7. Mass spectrum (MS) and tentative identified structure of the anthocyanin from the fruit peels of chinese flame tree $\left(\mathrm{ESI}=\mathrm{electrospray} \mathrm{ionization;}[\mathrm{M}+\mathrm{H}]^{+}=\right.$ molecular ion; and $\left[\mathrm{Y}_{0}\right]^{+}$and $\left[\mathrm{Y}_{1}\right]^{+}=$fragment ions). 
C. morifolium (Sun et al., 2010), Lycoris longituba (He et al., 2011), Nymphaea species (Zhu et al., 2012), and hybrids of pinkflowered Fragaria species (Xue et al., 2016).

The HPLC analysis revealed that the anthocyanin composition in the fruit peels of chinese flame tree was not complex. By using HPLC-ESI-MS, the major anthocyanin component was identified as cyanidin 3-Orutinoside. This anthocyanin accounts for more than $75 \%$ of the anthocyanin content in the dark red fruit peels of ripe lychee, which is another plant in the Sapindaceae family (Rivera-López et al., 1999). Moreover, cyanidin 3-O-rutinoside has been found in the fruit of many other plants, such as acai berry [Euterpe oleracea (Gouvêa et al., 2012)], sweet cherry [Prunus avium (Hayaloglu and Demir, 2015)], and black mulberry [Morus nigra (Chen et al., 2016)], and it is one of the major pigments in the red internal petals of Chimonanthus praecox (Ge et al., 2008). Based on the anthocyanin analysis, we can speculate its biosynthetic pathway in fruit of chinese flame tree (Fig. 8). The biosynthesis of anthocyanins is a part of flavonoid biosynthetic pathway, which uses 4-coumaroyl CoA and malonyl CoA as precursors. With the activities of a series of enzymes, the pathways would be leading to different kind of anthocyanins (Tanaka et al., 2008). However, in our research, regardless of red group, pink group, or green group, cyanidin derivative was detected to be the dominated anthocyanin in the fruit. Therefore, the fruit of chinese flame tree may only possess branched anthocyanin metabolic pathway of cyanidin. According to these, combing with the expression levels of related genes, the key branch point, leading to the difference of biosynthetic flux in plants of chinese flame tree, could be found for molecular plant breeding in the future study.

\section{Conclusions}

Although chinese flame tree has been cultivated widely as an ornamental plant in southern China, it has not been divided into different cultivars. Fruit color is an important phenotypic trait of chinese flame tree. In the present investigation, a classification of these plants was performed based on their color phenotypes, and three groups with different fruit colors were designated. In addition, the relationships between phenotypes and pigments in the fruit peels were described. The results showed that anthocyanins, which mainly consisted of cyanidin 3-O-rutinoside, were the primary contributors to the variation and coloration of fruit peels. This work provides a basis for further

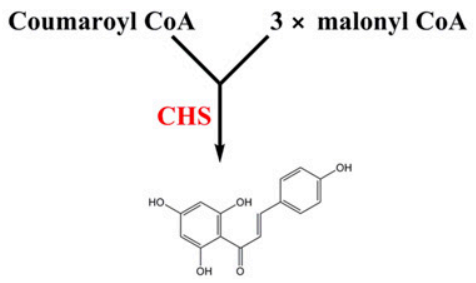

$4,2^{\prime}, 4^{\prime}, 6^{\prime}$-Tetrahydroxychalcone

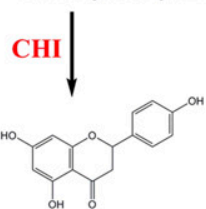

Naringenin

F3H

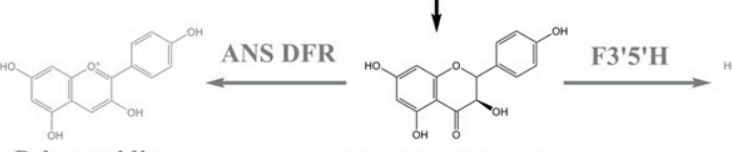

Dihydrokaempferol

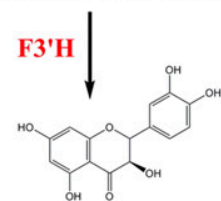

Dihydroquercetin

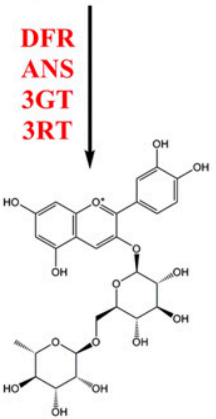

Cyanidin 3-O-rutinoside

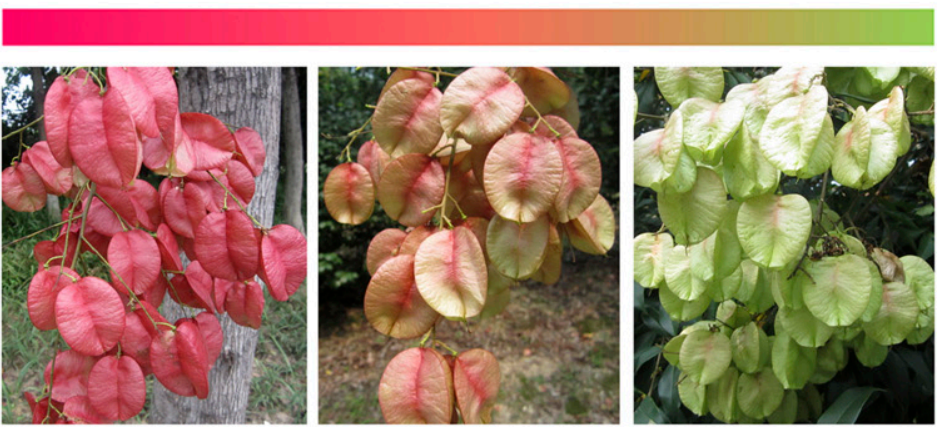

Fig. 8. Diagram of probable anthocyanin biosynthetic pathway in fruit of chinese flame tree (CHS = chalcone synthase; $\mathrm{CHI}=$ chalcone isomerase; $\mathrm{F} 3 \mathrm{H}=$ flavanone 3-hydroxylase; $\mathrm{F} 3{ }^{\prime} \mathrm{H}+$ flavonoid $3^{\prime}$ hydroxylase; F3' $5^{\prime} \mathrm{H}=$ flavonoid 3', 5' -hydroxylase; DFR = dihydroflavonol 4-reductase; ANS = anthocyanidin synthase; $3 \mathrm{GT}=$ anthocyanidin 3-O-glucosyltransferase; and 3RT $=$ anthocyanidin-3glucoside rhamnosyltransferase). The gray color indicates inexistent pathway in this research.

researching genetic control and regulation of anthocyanin biosynthesis genes on pigment accumulation and peel coloration of chinese flame tree. 


\section{Literature Cited}

Bai, X.X., K. Hu, S.L. Dai, and L.S. Wang. 2006. Components of flower pigments in the petals of different color Chrysanthemum morifolium Ramat. cultivars. J. Beijing For. Univ. 28:84-89. (in Chinese with English abstract).

Charoenchongsuk, N., K. Ikeda, A. Itai, A. Oikawa, and H. Murayama. 2015. Comparison of the expression of chlorophyll-degradationrelated genes during ripening between stay-green and yellow-pear cultivars. Scientia Hort. 181:89-94.

Chen, H., J. Pu, D. Liu, W. Yu, Y. Shao, G. Yang, Z. Xiang, and N. He. 2016. Anti-inflammatory and antinociceptive properties of flavonoids from the fruits of black mulberry (Morus nigra L.). PLoS One 11:e0153080.

Cooper-Driver, G.A. 2001. Contributions of Jeffrey Harborne and coworkers to the study of anthocyanins. Phytochemistry 56:229-236.

Ge, Y.X., L.S. Wang, Y.J. Xu, Z.A. Liu, C.H. Li, and N. Jia. 2008. Flower color, pigment composition and their changes during flowering in Chimonanthus praecox Link. Acta Hort. Sinica 35:1331-1338. (in Chinese with English abstract).

Gonnet, J.F. 1998. Colour effects of co-pigmentation of anthocyanins revisited-1. A colorimetric definition using the CIELAB scale. Food Chem. 63:409-415.

Gouvêa, A.C.M.S., M.C.P.D. Araujo, D.F. Schulz, S. Pacheco, R.L.D. O. Godoy, and L.M.C. Cabral. 2012. Anthocyanins standards (cyanidin-3-O-glucoside and cyanidin-3-O-rutinoside) isolation from freeze-dried acai (Euterpe oleraceae Mart.) by HPLC. Food Sci. Technol. 32:43-46.

Green, B.R. and D.G. Durnford. 1996. The chlorophyll-carotenoid proteins of oxygenic photosynthesis. Annu. Rev. Plant Physiol. Plant Mol. Biol. 47:685-714.

Grotewold, E. 2006. The genetics and biochemistry of floral pigments. Annu. Rev. Plant Biol. 57:761-780.

Harborne, J.B. 1963. Plant polyphenols IX. The glycosidic pattern of anthocyanin pigments. Phytochemistry 2:85-97.

Hayaloglu, A.A. and N. Demir. 2015. Phenolic compounds, volatiles, and sensory characteristics of twelve sweet cherry (Prunus avium L.) cultivars grown in Turkey. J. Food Sci. 81:7-18.

He, Q.L., S. Ye, M.X. Wang, M.R. Huang, R.Z. Yang, S.J. Zhu, L.S. Wang, Y.J. Xu, and R.L. Wu. 2011. Natural variation in petal color in Lycoris longituba revealed by anthocyanin components. PLoS One 6:e22098.

Hirschberg, J. 2001. Carotenoid biosynthesis in flowering plants. Curr. Opin. Plant Biol. 4:210-218.

Honda, C., N. Kotoda, M. Wada, S. Kondo, S. Kobayashi, J. Soejima, Z. Zhang, T. Tsuda, and T. Moriguchi. 2002. Anthocyanin biosynthetic genes are coordinately expressed during red coloration in apple skin. Plant Physiol. Biochem. 40:955-962.

Hong, Y., X.X. Bai, W. Sun, F.W. Jia, and S.L. Dai. 2012. The numerical cassification of chrysanthemum flower color phenotype. Acta Hort. Sinica 39:1330-1340. (in Chinese with English abstract).

Liang, S.F., B. Han, Z.F. Tie, and B.L. Ma. 2005. Extraction and microemulsion thin layer chromatography analysis of Koelreuteria henryi flavonoids. Acta Bot. Boreali-Occidential Sin. 25:186-190. (in Chinese with English abstract).

Lichtenthaler, H.K. 1987. Chlorophylls and carotenoids: Pigments of photosynthetic biomembranes. Methods Enzymol. 148:350-382.

Lin, C.H., H.S. Chang, and I.S. Chen. 2014. Chemical constituents and cytotoxic activity from the fruits of Koelreuteria henryi. Planta Med. 80:1542.

Ma, Y.L., F. Cuyckens, V.D.H. Heuvel, and M. Claeys. 2001. Mass spectrometric methods for the characterisation and differentiation of isomeric O-diglycosyl flavonoids. Phytochem. Anal. 12:159-165.
Ohmiya, A. 2013. Qualitative and quantitative control of carotenoid accumulation in flower petals. Scientia Hort. 163:10-19.

Ortega-Regules, A., I. Romero-Cascales, J.M. López-Roca, J.M. RosGarcía, and E. Gomez-Plaza. 2006. Anthocyanin fingerprint of grapes: Environmental and genetic variations. J. Sci. Food Agr. 86:1460-1467.

Patil, G. and K.S.M.S. Raghavarao. 2007. Integrated membrane process for the concentration of anthocyanin. J. Food Eng. 78:1233-1239.

Rivera-López, J., C. Ordorica-Falomir, and P. Wesche-Ebeling. 1999. Changes in anthocyanin concentration in lychee (Litchi chinensis Sonn.) pericarp during maturation. Food Chem. 65:195-200.

Rungpichayapichet, P., B. Mahayothee, P. Khuwijitjaru, M. Nagle, and J. Müller. 2015. Non-destructive determination of $\beta$-carotene content in mango by near-infrared spectroscopy compared with colorimetric measurements. J. Food Compos. Anal. 38:32-41.

Sun, W., C.H. Li, L.S. Wang, and S.L. Dai. 2010. Analysis of anthocyanins and flavones in different-colored flowers of chrysanthemum. Chinese Bul. Bot. 45:327-336. (in Chinese with English abstract)

Sun, W., C.H. Li, L.S. Wang, S.L. Dai, and Y.J. Xu. 2009. Anthocyanins present in flowers of Senecio cruentus with different colors. Acta Hort. Sinica 36:1775-1782. (in Chinese with English abstract).

Tanaka, Y., N. Sasaki, and A. Ohmiya. 2008. Biosynthesis of plant pigments: Anthocyanins, betalains and carotenoids. Plant J. 54:733749

Wei, X., C. Chen, Q. Yu, A. Gady, Y. Yu, G. Liang, and F.G. Gmitter. 2014. Novel expression patterns of carotenoid pathway-related genes in citrus leaves and maturing fruits. Tree Genet. Genomes 10:439448.

Wu, J., F.Y. Chen, and Y. Zhong. 2016. The numerical classification of flower color phenotype in flare tree peony. Acta Hort. Sinica 43:947956. (in Chinese with English abstract).

Xue, L., Z. Wang, W. Zhang, Y. Li, J. Wang, and J. Lei. 2016. Flower pigment inheritance and anthocyanin characterization of hybrids from pink-flowered and white-flowered strawberry. Scientia Hort. 200:143-150.

Yang, G.S. 2008. Studies on the best extraction of red pigment from Paniculed Gold -rain tree fruit peel. China Condiment 33:59-61. (in Chinese with English abstract).

Yang, R.Z., X.L. Wei, F.F. Gao, L.S. Wang, H.J. Zhang, Y.J. Xu, C.H. Li, Y.X. Ge, J.J. Zhang, and J. Zhang. 2009. Simultaneous analysis of anthocyanins and flavonols in petals of lotus (Nelumbo) cultivars by high-performance liquid chromatography-photodiode array detection/ electrospray ionization mass spectrometry. J. Chromatography 1216:106-112.

Yuan, Q., X.H. Pu, O.Y. Zhanmu, Z. Li, M.F. Chen, Y.F. Zhou, and L. L. Cui. 2013. Orthogonal test in extraction of total flavone from the peels of Koelreuteria paniculata by reflux method. J. Henan Univ. Medical Sci. 32:101-104. (in Chinese with English abstract).

Zhao, Ch.L., W.M. Guo, and J.Y. Chen. 2004. Preliminary study on the categories and contents of the flower color pigments of Prunus mume Sieb. et Zucc. J. Beijing For. Univ. 26:68-73. (in Chinese with English abstract).

Zhao, X., Z. Yuan, Y. Yin, and L. Feng. 2015. Patterns of pigment changes in pomegranate (Punica granatum L.) peel during fruit ripening. Acta Hort. 1089:83-89.

Zhu, M.L., L.S. Wang, H.J. Zhang, Y.J. Xu, X.C. Zheng, and L.J. Wang. 2012. Relationship between the composition of anthocyanins and flower color variation in hardy water lily (Nymphaea spp.) cultivars. Chinese Bul. Bot. 47:437-453. (in Chinese with English abstract). 